\section{Priscilla Marcondelli Dias Thomaz'}

\section{Teresa Helena Macedo da Costa}

Eduardo Freitas da Silva"

Pedro Curi Hallal"'
Faculdade de Ciências da Saúde. Universidade de Brasília (UnB). Brasília, DF, Brasil

" Departamento de Estatística. Instituto de Ciências Exatas. UnB. Brasília, DF, Brasil

III Programa de Pós-Graduação em Epidemiologia. Universidade Federal de Pelotas. Pelotas, RS, Brasil

\section{Correspondence:}

Priscilla Marcondelli Dias Thomaz Departamento de Nutrição

Universidade de Brasília

70910-900, Brasília, DF

E-mail: priscilla.nutricionista@gmail.com

Received: 9/16/2009

Approved: 3/15/2010

Article available from: www.scielo.br/rsp

\section{Factors associated with physical activity in adults in Brasília, Central-West Brazil}

\begin{abstract}
OBJECTIVE: To describe physical activity practice in adults and to identify associated factors.

METHODS: A cross-sectional study was performed with cluster sampling from the four areas of the city of Brasília, Central-West Brazil, in 2006-2007. A sample comprised of 469 adults was obtained from 250 randomly selected households. Sociodemographic data, weight and height were obtained during a household interview. The short version of the International Physical Activity Questionnaire (IPAQ) was used to measure physical activity. A multivariate linear regression analysis was made to assess the effect of sex, body mass index (BMI), socioeconomic classification and marital status on physical activity scores.
\end{abstract}

RESULTS: The majority of the sample was comprised of women (57\%). The percentage of individuals who achieved 150 minutes of weekly physical activity practice was $52 \%(95 \% \mathrm{CI}: 47 ; 56)$, while that of inactive individuals was $21.5 \%$ (95\% CI: $17.8 ; 25.3)$. An inverse association between physical activity and BMI was only found in men. Types of physical activity reported differed between sexes: walking and doing household chores among women; cycling, running, swimming and weight-lifting among men. There was a strong interaction between male sex and BMI in terms of the association with physical activity scores: the higher the BMI, the lower the physical activity score.

CONCLUSIONS: The portion of inactive individuals in Brasília can be considered low, when compared to estimates from other Brazilian cities. Differences in BMI and physical activity score found between sexes are associated with the type of physical activity practiced.

DESCRIPTORS: Adult. Motor Activity. Body Mass Index. Socioeconomic Factors. Gender and Health. Cross-Sectional Studies.

\section{INTRODUCTION}

Physical activity practice is related with the prevention of non-communicable chronic diseases and improvement of general health and quality of life. ${ }^{3}$ Regular physical activity practice reduces the risk of death from cardiovascular diseases by $35 \%$ and mortality from all causes by $33 \% .^{13}$

Physical activity is a complex type of behavior influenced by several factors such as age, socioeconomic level, education and sex. However, there are controversies about the influence of such factors on physical activity levels in the Brazilian population, especially because physical activity is basically present in four domains (leisure, work, household chores and commuting). Factors associated with physical activity practice in each domain are different. ${ }^{1,2,6}$ 
Brasilia is a city that offers its inhabitants the choice of exercising outdoors in several parks and on long, flat avenues. However, there is a small number of pedestrians in this city, due to the city's architecture, which is not designed for walking. On the other hand, there has been an increase in the number of fitness clubs, which promote physical activity practice even when it rains. Despite these options, it is hypothesized that a large portion of the Brazilian population is physically inactive. One characteristic of the adult population is that a great number are civil servants who work from six to eight hours a day and whose occupational activity is very light, involving mostly sitting.

The present study aimed to describe physical activity practice in adults and identify associated factors.

\section{METHODS}

A population-based, cross-sectional study was performed, with cluster random sampling. Sample size calculation was based on 82,680 households registered with the Companhia Energética de Brasília (Brasília Electric Company), whose coverage is $100 \%$.

Sample calculation maintained an alpha error of 5\% and considered the prevalence of physical activity lower than 150 minutes per week to be $80 \%$, according to a previous study with adult workers in Brasília, Federal District, Central-West Brazil. ${ }^{17}$ Thus, the sample totaled 250 households, maintaining the proportionality in each of the four sanitary areas of Brasília: Asa Sul (Southern District - 113 households, 45\%), Asa Norte (Northern District - 117 households, 47\%), Vila Planalto (Plateau District - ten households, 4\%) and Setor Militar Urbano (Urban Military District - ten households, 4\%). All residents aged 20 years or older were interviewed in each household, between March 2005 and November 2006.

A total of $53 \%$ of randomly selected households had to be replaced due to reasons such as: empty homes, business addresses, and refusal of all residents to participate in the study.

Refusal to participate totaled $13 \%$ of individuals, with a greater concentration in Vila Planalto. The sample of 469 individuals interviewed was obtained from the 250 households visited, of which 57\% were women.

A questionnaire was applied to collect identification, demographic and socioeconomic data, in addition to anthropometric measures and information about routine activities, such as: number of hours of sleep and time spent sitting, eating, watching television and using the computer. One question was designed for individuals to point out one reason to maintain their pattern of physical activity, comprised of 14 close-ended responses and one open-ended response. Responses were sub-divided in two parts, describing positive and negative aspects related with physical activity practice. The short version of the International Physical Activity Questionnaire (IPAQ) was used to analyze physical activity during work, leisure, household chores and commuting performed in the previous week.

The IPAQ is a questionnaire recommended by the World Health Organization (WHO) and used to estimate the level of routine physical activity practice in populations of different countries and socio-cultural contexts, having been validated on an international level ${ }^{5}$ and in Brazil. ${ }^{11}$ The IPAQ has a coefficient of validation and reproducibility similar to those of other instruments, although having the advantages of being practical and fast and enabling surveys of large populations, thus representing a great alternative to compare studies. ${ }^{11}$

All questionnaires were previously tested in a pilot study with 25 workers of a university center of Brasília and adjusted when necessary. Interviewers involved in this study were trained, aiming to standardize procedures. A total of five meetings with the team were held during collection to assess reproducibility among anthropometric pieces of equipment (scales and stadiometers) and among evaluators. With regard to the equipment, there was no significant difference in the analysis of variance $(p=0.14)$ among scales and among stadiometers $(\mathrm{p}=0.12)$. Moreover, no statistically significant difference in the analysis of variance was found in the assessment of reproducibility among evaluators $(p=0.22)$.

First of all, residents received a message by mail, informing them about the research objectives and the interviewers' visit. In the case of undecided residents or those who could not be easily reached, interviewers booked a visit at these residents' convenience. After signing the informed consent form, interviewers applied the questionnaire and measured residents' weight and height, according to the methodology proposed by Jelliffe (1996). ${ }^{9}$ A total of three digital scales with a 150 kilogram capacity and 100 gram accuracy (Plenna, São Paulo, Brazil) and three portable stadiometers (Alturexata, Belo Horizonte, Brazil), with a height range of 2.13 meters and 0.1 centimeter accuracy were used. These measurements were used to indirectly assess the nutritional status of individuals through their body mass index (BMI) and to compare weight and height values measured with those self-reported by participants in the questionnaires.

After the interview, interviewers gave an educational pamphlet about physical activity. All data of the questionnaire were completed during the interview and, in case clarifications were necessary, a telephone contact was subsequently made. The entire database was reviewed and possible typing and data entry errors were corrected. 
Physical activity levels were analyzed through the physical activity time, according to the recommendation of 150 minutes of activity per week. ${ }^{14,19}$ Weekly physical activity time was obtained by adding the minutes spent on walks and other moderate physical activities, and those spent on vigorous activities, multiplied by two. ${ }^{6}$ Participants were classified into four different levels of physical activity, according to the score obtained in minutes: 0 , inactive; from 1 to 149 , insufficiently active; from 150 to 499 , active; and $\geq 500$, very active. ${ }^{6}$ The type of physical activity most frequently practiced by each individual was categorized into five groups: 1. walking (both as transportation, leisure, pleasure or exercise, whether accompanied or not); 2. cycling, running or swimming; 3. group activities (group sports); 4. body building (exercises with weights); and 5. household chores.

The BMI was classified according to WHO criteria. ${ }^{20}$

The Brazilian Economic Classification Criterion ${ }^{a}$ was used to assess purchasing power.

Results were initially analyzed using descriptive statistics. Multivariate linear regression analysis was performed to assess the effect of sex, BMI, socioeconomic classification and marital status on the physical activity score.

The variance inflation index indicated that independent variables did not show collinearity among themselves, all of which had a value close to one.

Rao-Scott chi-square test was used to assess the association between type of activity and sex, age, socioeconomic classification and BMI. This test is a Pearson chi-square test corrected for the complex design effect used in this study. ${ }^{16}$

All information was tabulated in a spreadsheet and analyzed in the SAS software, version 9.1.3, using a significance level of $\mathrm{p}<0.05$.

The present study was approved by the Research Ethics Committee of Faculdade de Ciências da Saúde da Universidade de Brasília on Dec. $9^{\text {th }}, 2004$ (Protocol 101/2004) and all participants signed an informed consent form.

\section{RESULTS}

Mean age was 44 years $(\mathrm{SD}=16)$, varying from 20 to 91 years. With regard to the socioeconomic classification, $81 \%$ of individuals belonged to groups with a higher socioeconomic level (A and B), 12\% to group C, and $7 \%$ to groups D and $\mathrm{E}$. Mean level of education was 13 years, varying between 9 and 17 years and with a median of 15 years. In terms of marital status, $57 \%$ were married, $30 \%$ single, $10 \%$ divorced, and $3 \%$ widowed. In addition, as regards weekly physical activity practice, $22 \%$ of individuals were considered inactive, $26 \%$ were insufficiently active, $35 \%$ were active, and $17 \%$ were very active (Table).

Among the five types of physical activity categorized, walking was the most frequent one, followed by group activities and weightlifting (Table). Rao-Scott chi-square test showed an association between type of physical activity and $\operatorname{sex}(\mathrm{p}=0.0092)$, indicating that men perform more activities such as running, swimming, cycling and weightlifting, whereas women perform more walking and household chores.

When asked about the "reason for maintaining a pattern of physical activity", $55 \%$ of individuals directed their responses towards the main reason for them to practice exercises and $45 \%$ reported the main reason for being inactive. The great majority of individuals $(52.4 \%)$ stated that they practiced physical activity to improve their health and quality of life; $18 \%$, due to aesthetic factors or because it was mandatory; $16.8 \%$, for pleasure; and $12.8 \%$, due to a doctor's recommendation. In contrast, $51 \%$ of individuals justified the negative behavior towards physical activity practice due to lack of time; $27.4 \%$, due to lack of willingness; $5.8 \%$, due to health problems; and $15.8 \%$, for other reasons (dislike for, unfavorable climate, lack of habit, lack of financial resources and lack of an adequate place).

With regard to weight and height values measured and self-reported, the measured weight tended to be very close to that reported on average, while the measured height tended to be, on average, slightly lower than that reported (results not shown).

In terms of the BMI, $52.7 \%$ of individuals were eutrophic (of these, $1.5 \%$ were underweight), $32.6 \%$ were overweight and $14.7 \%$ were obese. The female sex was associated with lower BMI and the male sex with higher BMI $(\mathrm{p}<0.0001)$ (Table).

Based on the result of multivariate linear regression, the interaction between sex and BMI was significant in men only $(\mathrm{p}=0.026)$ : the higher the BMI, the lower the physical activity score (Figure).

\section{DISCUSSION}

Results of the present study showed the association between sex and BMI related to the physical activity score, especially in men.

The reason for this finding may be related to the association observed between type of physical activity and sex, where men perform rigorous activities, such as

a Associação Nacional de Empresas de Pesquisa. Critério de classificação econômica Brasil. São Paulo, 1996. 
Table. Distribution of the sample of adults, according to physical activity score, type of physical activity, and body mass index by sex. City of Brasília, Central-West Brazil, 2006-2007.

\begin{tabular}{|c|c|c|c|c|c|c|}
\hline \multirow[t]{2}{*}{ Variable } & \multicolumn{2}{|c|}{$\begin{array}{c}\text { Male } \\
(\mathrm{n}=203)\end{array}$} & \multicolumn{2}{|c|}{$\begin{array}{c}\text { Female } \\
(\mathrm{n}=266)\end{array}$} & \multicolumn{2}{|c|}{$\begin{array}{c}\text { Total } \\
(\mathrm{n}=469)\end{array}$} \\
\hline & $\mathrm{n}$ & $\%$ & $\mathrm{n}$ & $\%$ & $\mathrm{n}$ & $\%$ \\
\hline \multicolumn{7}{|c|}{ Activity score (150min of physical activity per week) } \\
\hline Inactive & 45 & 22.2 & 56 & 21.0 & 101 & 21.5 \\
\hline Insufficiently active & 43 & 21.2 & 79 & 29.7 & 122 & 26.0 \\
\hline Active & 75 & 36.9 & 92 & 34.6 & 167 & 35.6 \\
\hline Very active & 40 & 19.7 & 39 & 14.7 & 79 & 16.8 \\
\hline Total & 203 & 100 & 266 & 100 & 469 & 100 \\
\hline \multicolumn{7}{|l|}{ Type of physical activity } \\
\hline Inactive & 46 & 22.7 & 57 & 21.4 & 103 & 22.0 \\
\hline Walking & 53 & 26.1 & 92 & 34.6 & 145 & 30.9 \\
\hline Group activity & 29 & 14.3 & 31 & 11.7 & 60 & 12.8 \\
\hline Weightlifting & 31 & 15.3 & 29 & 10.9 & 60 & 12.8 \\
\hline Cycling / running / swimming & 31 & 15.3 & 19 & 7.1 & 50 & 10.7 \\
\hline Household chores & 13 & 6.4 & 38 & 14.3 & 51 & 10.9 \\
\hline Total & 203 & 100 & 266 & 100 & 469 & 100 \\
\hline \multicolumn{7}{|l|}{ Body Mass Index $\left(\mathrm{kg} / \mathrm{m}^{2}\right)$} \\
\hline$<18.5$ & 1 & 0.5 & 6 & 2.3 & 7 & 1.5 \\
\hline 18.6 to 24.9 & 83 & 40.9 & 157 & 59.0 & 240 & 51.2 \\
\hline 25 to 29.9 & 88 & 43.3 & 65 & 24.4 & 153 & 32.6 \\
\hline$\geq 30$ & 31 & 15.3 & 38 & 14.3 & 69 & 14.7 \\
\hline Total & 203 & 100 & 266 & 100 & 469 & 100 \\
\hline
\end{tabular}

running, swimming, cycling and weightlifting. Women, on the other hand, walk and do household chores more frequently. Similarly, the study with 1,664 workers performed by McMurray et al ${ }^{12}$ (1998) concluded that the higher the physical activity level, the lower the body fat level and weight of male individuals, an association not found in women. Huang et $\mathrm{al}^{8}$ (1998) found more active individuals with lower BMI in both sexes, in a sample comprised of 3,495 men and 1,175 women aged more than 40 years. In a study with women $(n=39,972)$ conducted by Lee et $\mathrm{al}^{10}(2001)$, it was observed that those who were more active had a lower mean BMI than those less active. Recognition of the differences between sexes could be important to design intervention strategies for physical activity practice in the population of Brasília.

The results found differ from those observed in other studies, especially due to the several forms of operationalization of variables related to physical activity practice and due to the several instruments used for this purpose. The Brazilian Health Ministry, in a health surveillance survey conducted by telephone in 2007, ${ }^{\text {b }}$ reported that the frequency of adults who practice sufficient physical activity in their leisure time was low in all cities studied, varying from $11.3 \%$ in São Paulo (SP) to $20.5 \%$ in Vitória (ES), both in southeastern region. In the Federal District, there was a percentage of $17.2 \%$ in which more men practice sufficient physical activity in their leisure time than women. ${ }^{\mathrm{b}}$ As the present study assessed the activities performed in the four domains, it would be inadequate to compare findings. In the same survey performed by the Health Ministry, ${ }^{b}$ the frequency of adults (of both sexes) who were sufficiently active in their leisure time increased according to individuals' level of education.

This association was not found in the present study, probably due to the small heterogeneity of socioeconomic level in the sample.

According to the Health Ministry, ${ }^{b}$ the majority of the Brazilian population do not meet the minimum physical activity practice levels to guarantee health improvements. A high frequency of physical inactivity was found in adults in all cities studied, varying from $24.9 \%$ in Porto Velho to $32.8 \%$ in Recife, northern and northeastern regions, respectively, and, on average, $29 \%$ of individuals were considered inactive and almost half of them were above normal weight. ${ }^{b}$

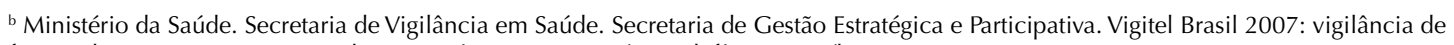
fatores de risco e proteção para doenças crônicas por inquérito telefônico.Brasília, DF; 2008. 


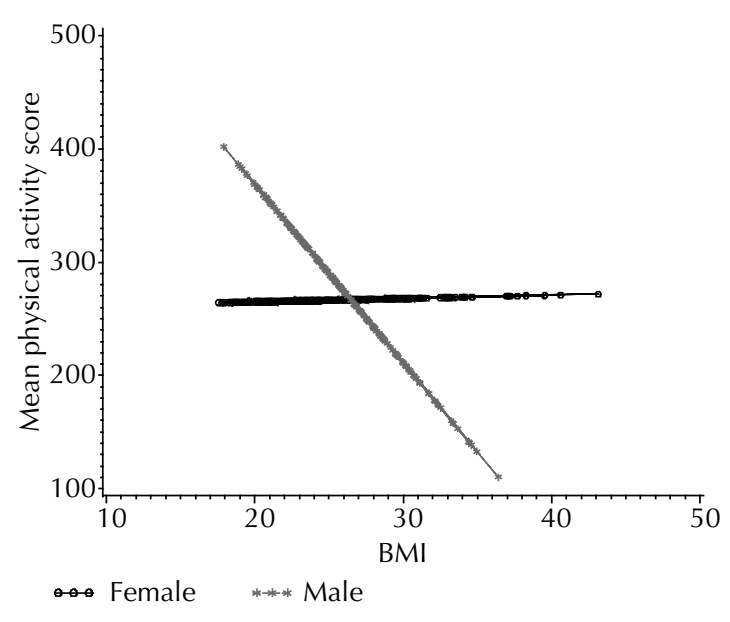

$\overline{\text { Figure. Effect of the interaction between sex and body mass }}$ index on the physical activity score. City of Brasília, CentralWest Brazil, 2006-2007.

Obesity and inactivity are relevant to health, once they are associated with several chronic diseases, especially cardiovascular ones. ${ }^{4,15,18}$

A study performed with 3,100 individuals by Hallal et $\mathrm{al}^{7}$ (2008) in Pelotas (RS), Southern Brazil, also used the IPAQ and classified individuals into groups with "normal" $\left(<25.0 \mathrm{~kg} / \mathrm{m}^{2}\right)$, "overweight" $(25-29.9 \mathrm{~kg} /$ $\left.\mathrm{m}^{2}\right)$ and "obese" BMI $\left(\geq 30 \mathrm{~kg} / \mathrm{m}^{2}\right)$. Like in the present study, there was no difference between BMI and physical activity level. However, more individuals with adequate BMI were considered insufficiently active $(71.6 \%)$, when compared to the present study $(48 \%)$. One hypothesis for the divergence of results could be associated with favorable aspects in the city of Brasília, such as the high socioeconomic and educational levels (mean of 13 years of education) of the sample studied, variables related to awareness of and involvement with physical activities, ${ }^{\mathrm{b}}$ whereas the mean level of education was eight years in the study of Pelotas.

In addition to individual aspects, the city includes unique and architectural features that promote physical activity, such as: flatness of most of the city, large and easily accessible parks, courts and areas equipped for gymnastics, and wide streets open for leisure and sports on Sundays, among others. These factors promote shortterm interventions, aiming to increase the number of residents practicing physical activities. Activities that promote gymnastics on courts in Brasília, bicycle trips on weekends and leisure activities in the city parks can, little by little, raise the population's awareness of the importance of regular physical activity to improve their health. Such activities must be aimed at encouraging men and, especially, women to perform more intense physical activities.

Moreover, long-term measures to promote physical activity should be implemented, such as: improvement of the road system, revitalization of commerce close to residential areas, and construction of more accessible pedestrian and safer bicycle paths. The city does not enable individuals to be independent from automotive transportation, thus leading to the population's physical inactivity, in addition to increasing environmental pollution.

In conclusion, differences in physical activities between men and women living in Brasília are useful to direct intervention actions towards increasing the physical activity practice in this population. 


\section{REFERENCES}

1. Azevedo MR, Araújo CL, Reichert FF, Siqueira FV, da Silva MC, Hallal PC. Gender differences in leisure-time physical activity. Int J Public Health. 2007;52(1):8-15.

2. Baretta E, Baretta M, Peres KG. Nível de atividade física e fatores associados em adultos no Município de Joaçaba, Santa Catarina, Brasil. Cad Saude Publica. 2007;23(7):1595-602. DOI:10.1590/S0102311 X2007000700010

3. Bauman AE. Updating the evidence that physical activity is good for health: an epidemiological review 2000-2003 . J Sci Med Sport. 2004;7(1 Suppl):6-19.

4. Berlin JA, Colditz GA. A meta-analysis of physical activity in the prevention of coronary heart diseases. Am J Epidemiol. 1990;132(4):612-28.

5. Craig $C L$, Marshall $A L$, Sjöström $M$, Bauman $A E$, Booth $\mathrm{ML}$, Ainsworth BE, et al. International physical activity questionnaire: 12 -Country reliability and validity. Med Sci Sports Exerc. 2003;35(8):1381-95.

6. Hallal PC, Victora CG, Wells JC, Lima RC. Physical inactivity: prevalence and associated variables in Brazilian adults. Med Sci Sports Exerc. 2003;35(11):1894-900.

7. Hallal PC, Reichert FF, Siqueira FV, Dumith SC, Bastos JP, Silva MC, et al. Correlates of leisure-time physical activity differ by body-mass-index status in Brazilian adults. J Phys Act Health. 2008;5(4):571-8.

8. Huang Y, Macera CA, Blair SN, Brill PA, 3rd Kohl HW, Kronenfeld JJ. Physical fitness, physical activity, and functional limitation in adults aged 40 and older. Med Sci Sports Exerc. 1998;30(9):1430-5.

9. Jelliffe DB. The assessment of the nutritional status of the community. Geneva: WHO; 1966.

10. Lee IM, Rexrode KM, Cook NR, Manson JE, Buring JE. Physical activity and coronary heart disease in women: is "no pain, no gain" passé? JAMA. 2001;285(11):1447-54.

11. Matsudo S, Araújo T, Matsudo V, Andrade D, Andrade E, Oliveira LC, et al. Questionário internacional de atividade física (IPAQ): estudo de validade e reprodutibilidade no Brasil. Rev Bras Ativ Fis Saude. 2001;6(2):5-18.

12. McMurray RG, Ainsworth BE, Harrell JS, Griggs TR, Williams OD. Is physical activity or aerobic power more influential on reducing cardiovascular disease risk factors? Med Sci Sports Exerc. 1998;30(10):1521-9.

13. Nocon M, Hiemann T, Müller-Riemenschneider F, Thalau F, Roll S, Willich SN. Association of physical activity with all-cause and cardiovascular mortality: a systematic review and meta-analysis. Eur J Cardiovasc Prev Rehabil. 2008;15(3):239-46.

14. Pate RR, Pratt M, Blair SN, Haskell WL, Macera CA, Bouchard C, et al. Physical activity and public health. A recommendation from the Centers for Disease Control and Prevention and the American College of Sports Medicine. JAMA. 1995;273(5):402-7.

15. Pereira MA, Folsom AR, McGovern PG, Carpenter M, Arnett DK, Liao D, et al. Physical activity and incident hypertension in black and white adults: the Arteriosclerosis Risk in Communities Study. Prev Med. 1999;28(3):304-12.

16. Rao JNK, Scott AJ. The analysis of categorical data from complex sample surveys: Chi-squared tests for goodness of fit the independence in two-way tables. I Am Stat Assoc. 1981;76(374):221-30.

17. Savio KEO, Costa THM, Schmitz BAS, Silva EF. Sexo, renda e escolaridade associados ao nível de atividade física de trabalhadores. Rev Saude Publica. 2008;42(3):457-63. DOI:10.1590/S003489102008005000018

18. Sternfeld B. Cancer and the protective effect of physical activity: the epidemiological evidence. Med Sci Sports Exerc. 1992;24(11):1195-209.

19. USA. Department of Health and Human Services. Physical activity and health: a report of the surgeon general. Atlanta; 1996.

20. World Health Organization (WHO). Obesity: preventing and managing the global epidemic. Geneva; 1997. 